\title{
PENGARUH KUALITAS WEBSITE LEMBAGA PENERBANGAN DAN ANTARIKSA NASIONAL TERHADAP KEPUASAN PENGGUNA DENGAN METODE WEBQUAL
}

\section{QUALITY EFFECT OF LEMBAGA PENERBANGAN DAN ANTARIKSA NASIONAL'S WEBSITE ON USER SATISFACTION WITH THE WEBQUAL METHOD}

\author{
Igif G Prihanto ${ }^{1}$, Budhi Riyanto ${ }^{2}$, Suwardi $^{3}$, Hendy Gunawan ${ }^{4}$, Elly Kuntjahyowati ${ }^{5}$, Arief \\ Indriarto Haris ${ }^{6}$, Ardito Adi Ramadhan \\ ${ }_{1,2,3,4,5,6,7}$ Pusat Teknologi Informasi dan Komunikasi Penerbangan dan Antariksa \\ Jalan Pemuda Persil No.1 Jakarta Timur, Indonesia

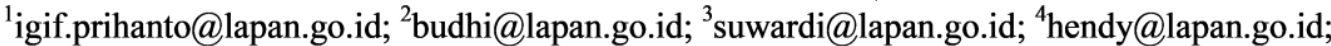 \\ ${ }^{5}$ Elly.Kuntjahyowati@lapan.go.id; ' arief.indriarto@lapan.go.id; ' ardito.adi@lapan.go.id
}

Diterima tgl. 12/08/2020; Direvisi tgl. 19/10/2020; Disetujui tgl. 1/11/2020

\begin{abstract}
In early 2020, LAPAN launched the latest version of the website with updated look and features. The problem is that the quality of the LAPAN website has not been able to satisfy users. This study aims to determine the effect of the LAPAN website on user satisfaction with the WebQual method. Respondents are LAPAN employees at the LAPAN Work Unit who have used or interacted with the LAPAN website. The number of samples taken 193 respondents by purposive sampling based on the Slovin formula. The validity and reliability test results of the research instruments are valid and reliable because they meet the requirements. The results are (1) the multiple regression equation model to user satisfaction is $Y=0.305+0.067$ Usability + 0.016 Information Quality + 0.037 Service Interaction Quality; (2) the Usability, Information Quality, and Service Interaction Quality variables have a positive and significant effect on LAPAN website user satisfaction; (3) the Usability variable and Service Interaction Quality variable have positive and partially significant effect on LAPAN website user satisfaction, while the Information Quality variable has no positive and significant effect on LAPAN website user satisfaction; and (4) Usability, Information Quality and Service Interaction Quality variables contributed 58.4\% to LAPAN website user satisfaction, while the remaining $41.6 \%$ was influenced by other independent variables.
\end{abstract}

Keywords: User Satisfaction, Webqual 4.0, Multiple Linear Regression

\begin{abstract}
ABSTRAK
Di awal tahun 2020, LAPAN telah melakukan peluncuran website versi terbaru dengan tampilan dan fitur yang telah diperbarui. Permasalahannya adalah kualitas website LAPAN tersebut belum dapat memuaskan pengguna. Untuk itu penelitian ini bertujuan melihat mengetahui pengaruh website LAPAN terhadap kepuasan pengguna dengan metode WebQual. Responden ialah pegawai LAPAN pada satuan kerja di lingkungan LAPAN yang pernah memanfaatkan atau berinteraksi dengan website LAPAN. Jumlah sampel yang diambil 193 responden secara purposive sampling berdasarkan rumus Slovin. Hasil uji validitas dan reliabilitas instrumen penelitian adalah valid dan reliabel karena telah memenuhi persyaratan. Hasil penelitian adalah (1) model persamaan regresi berganda untuk Kepuasan pengguna $\mathrm{Y}=0,305+0,067$ Usability $+0,016$ Information Quality + 0,037 Service Interaction Quality; (2) Variabel Usability, Information Quality, dan Service Interaction Quality berpengaruh positif dan signifikan secara simultan terhadap kepuasan pengguna website LAPAN; (3) Variabel Usability dan Service Interaction Quality berpengaruh positif dan signifikan secara parsial terhadap kepuasan pengguna website LAPAN, sedangkan variabel Information Quality tidak berpengaruh positif dan signifikan secara parsial terhadap kepuasan pengguna website LAPAN; dan (4) Variabel Usability, Information Quality dan Service Interaction Quality memberikan sumbangan pengaruh $58,4 \%$ terhadap kepuasan pengguna website LAPAN, sedangkan sisanya sebesar $41,6 \%$ dipengaruhi oleh variabel bebas lain.
\end{abstract}

Kata Kunci: Kepuasan Pengguna, Webqual 4.0, Regresi Linier Berganda 


\section{PENDAHULUAN}

Lembaga Penerbangan dan Antariksa Nasional (LAPAN) berdasarkan Peraturan Presiden Republik Indonesia Nomor 49 Tahun 2015 mempunyai tugas melaksanakan pemerintahan di bidang penelitian dan pengembangan kedirgantaraan dan pemanfaatannya serta penyelenggaraan keantariksaan sesuai dengan ketentuan peraturan perundang-undangan. Dalam pelaksanaan tugas tersebut, LAPAN sebagai lembaga pemerintah dalam mendukung penyelenggaraan pemerintahan berbasis elektronik telah meluncurkan website versi terbaru (www.lapan.go.id) di awal tahun 2020 sebagai pengganti website versi lama (Gambar 1).

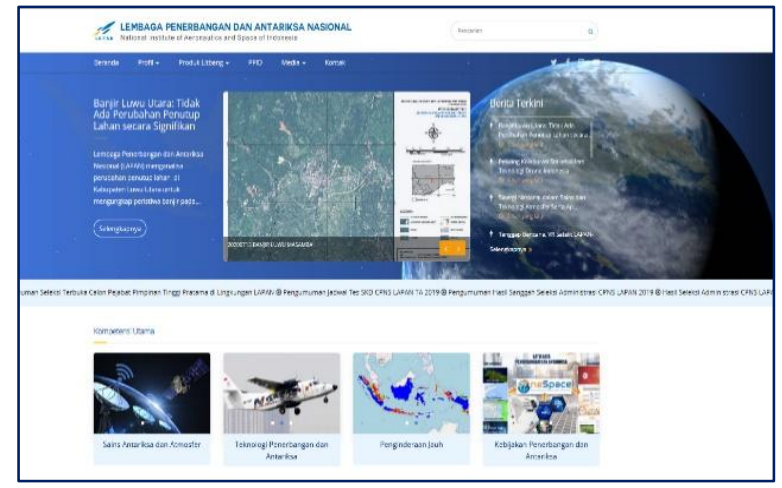

Gambar 1. Website LAPAN (LAPAN, 2020)

Website merupakan salah satu aplikasi dalam bentuk media informasi elektronik berbasis online yang dipublikasi melalui jaringan internet sebagai penghubung kepada pengguna untuk pertukaran data dan informasi yang dapat diakses dari manapun dan kapanpun (Napitupulu, 2016; Maslan, 2014). Kualitas website dapat_mempengaruhi persepsi pengunjung dan tingkat kepuasan pengguna website tersebut (Jamalludin, Sulistiowati, \& Lemantara, 2016) sehingga persepsi pengguna merupakan hal yang penting untuk dijadikan umpan balik terhadap pihak penyedia.

Kualitas website yang baik tentu tidak bisa hanya didasarkan dari sudut pandang pengelola, pembangun dan penyedia website, tetapi juga perlu didasarkan pada persepsi dari pengguna website. Kepuasan pengguna yang didasarkan pada penilaian atau persepsi dari pengguna dapat dijadikan sebagai ukuran keberhasilan dan keunggulan bagi pengelola dan penyedia website dalam rangka memenuhi kepentingan yang diharapkan pengguna.

Kualitas website dapat diukur dengan metode WebQual (Website Quality). WebQual merupakan suatu metode pengukuran kualitas website berdasarkan penilaian atau persepsi pengguna akhir (Chmielarz \& Zborowski, 2018; Sastika, 2016). Versi terakhir dari metode WebQual adalah WebQual 4.0 berdasarkan tiga dimensi utama, yaitu kualitas kegunaan (usability quality), kualitas informasi (information quality), dan kualitas layanan interaksi (service interaction quality) (Fatmala, Suprapto, \& Rachmadi, 2018; Santoso \& Anwar, 2015; Dewi \& Naya, 2020; Barus, Suprapto, \& Herlambang, 2018). Analisis regresi berganda merupakan suatu analisis untuk melihat ada tidaknya pengaruh yang signifikan secara parsial atau simultan antara dua atau lebih variabel bebas (independent) terhadap satu variabel terikat (dependent). Selain itu, juga untuk mengetahui bagaimana pengaruhnya apakah positif atau negatif dan seberapa besar pengaruhnya serta untuk memprediksi nilai variabel terikat dengan menggunakan variabel bebas (Prayitno, 2018).

Dalam memasuki era informasi dewasa ini, LAPAN telah membangun website yang digunakan untuk memberikan pelayanan kepada masyarakat pengguna. Namun, dalam implementasinya permasalahan yang muncul adalah kualitas website LAPAN belum dapat memuaskan pengguna. Hal ini disebabkan adanya beberapa pengguna yang beranggapan kualitas 
website tersebut masih menghadapi beberapa masalah sehingga kualitas yang dirasakan belum memuaskan pengguna, antara lain website memiliki tampilan yang kurang menarik, website kurang mengandung nilai kompetensi, website menyediakan informasi yang kurang aktual, website memiliki tata letak yang kurang terstruktur dan tidak konsisten.

Beberapa peneliti terdahulu telah melakukan hal yang sama untuk melihat kualitas website, seperti menganalisis kualitas layanan website Kementerian Kominfo (Sanjaya, 2012), menganalisis pengaruh kualitas website terhadap keputusan pembelian pada website E-Commerce Traveloka (Sastika, 2016), menganalisis pengaruh kualitas website terhadap kepuasan pengguna pada website Stikom Career Center (SCC) (Jamalludin, Sulistiowati, \& Lemantara, 2016), menganalisis kualitas website CV. Zamrud Multimedia Network (Syaifullah \& Soemantri, 2016), menganalisis pengaruh kualitas website terhadap kepuasan pengguna berdasarkan metode Webqual 4.0 pada Universitas Narotama (Wawoluamaya, Sunarto, \& Wulandari, 2016), menganalisis faktor yang mempengaruhi kualitas website berbasis Webqual pendekatan pada studi kasus: universitas XYZ (Napitupulu, 2017), menganalisis pengaruh kualitas website terhadap kepuasan pelanggan mister aladin dengan menggunakan Webqual 4.0 (Kurniawati, Kusyanti, \& Mursityo, 2018), menganalisis pengaruh kualitas website PPDB terhadap kepuasan pengguna (Utami, Ishaq, \& Maulidiyah, 2018), menganalisis pengaruh kualitas Website BPS Ka. Siak (Nofirman, Jalinus, \& Irfan, 2019), menganalisis kualitas layanan Website universitas XYZ terhadap kepuasan pengguna (Amelia \& Pradesan, 2019), dan menganalisis pengaruh kualitas website Backpacker Jakarta (Ispandi, Ramadan, Atmaja, \& Sudradjat, 2020).

Berdasarkan beberapa penelitian di atas dan dalam rangka memenuhi kebutuhan pengguna, LAPAN perlu melakukan evaluasi website LAPAN (www.lapan.go.id) dengan tujuan menganalisis pengaruh kualitas website LAPAN terhadap kepuasan pengguna. Evaluasi ini penting untuk dilakukan karena dalam mendukung reformasi birokrasi, kualitas website LAPAN tersebut dijadikan sebagai salah satu barometer untuk mengukur kinerja LAPAN dan kepuasan pengguna website juga menjadi ukuran utama kunci keberhasilan dari kualitas website LAPAN.

Pada penelitian ini kerangka pemikiran yang digunakan untuk menjawab tujuan tersebut adalah model Analisis Regresi Linier Berganda (Wardhana, 2015) sebagaimana disajikan pada Gambar 2.

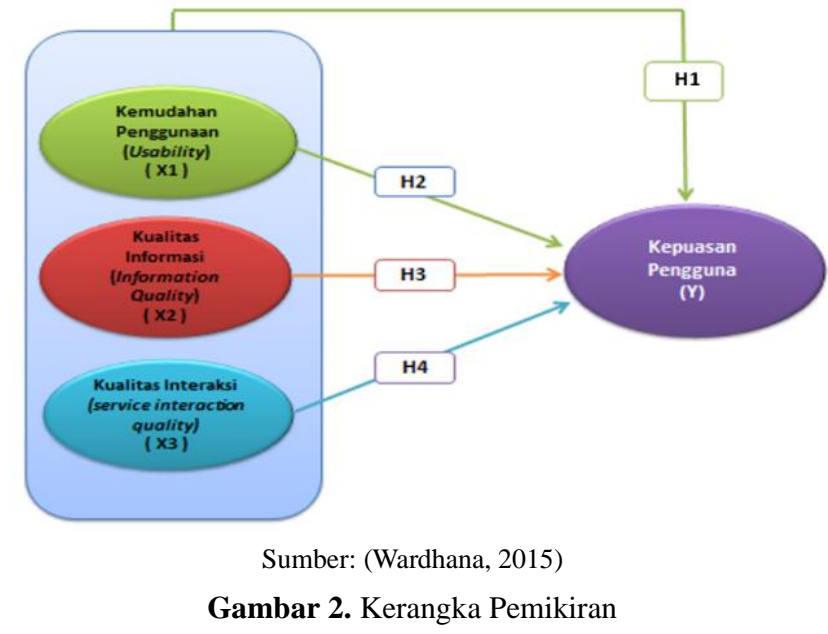

Berdasarkan kerangka pemikiran pada Gambar 2, yang menjadi variabel bebas adalah Usability (X1), variabel Information Quality (X2), dan variabel Service Interaction Quality (X3) dan yang menjadi variabel terikat adalah kepuasan pengguna website LAPAN (Y). Hipotesis yang diajukan pada penelitian ini adalah: (1) H1 adalah terdapat hubungan positif antara variabel Usability (X1), variabel Information Quality (X2), dan variabel Service Interaction Quality (X3) 
secara simultan terhadap kepuasan pengguna website LAPAN (Y); (2) H2 adalah terdapat hubungan positif antara variabel Usability (X1) secara parsial terhadap kepuasan pengguna website LAPAN (Y); (3) H3 adalah terdapat hubungan positif antara variabel Information Quality (X2) secara parsial terhadap kepuasan pengguna website LAPAN (Y); dan (4) H4 adalah terdapat hubungan positif antara variabel Service Interaction Quality (X3) secara parsial terhadap kepuasan pengguna website LAPAN (Y).

Manfaat yang diperoleh dari penelitian ini adalah memberikan bahan pertimbangan atau masukan kepada pimpinan LAPAN tentang tindakan apa saja yang harus dilakukan sebagai upaya peningkatan kualitas website LAPAN agar sesuai dan selaras dengan kepentingan dan harapan pengguna.

\section{METODE PENELITIAN}

Data penelitian adalah tanggapan responden terhadap kualitas website LAPAN melalui kuesioner google form yang disusun dengan skala empat poin skala Likert dimulai dari 1 (sangat tidak baik) sampai 4 (sangat Baik). Responden pada penelitian hanya terbatas pada pengguna internal LAPAN, yaitu pegawai LAPAN pada 21 satuan kerja di lingkungan LAPAN yang pernah memanfaatkan atau berinteraksi dengan website LAPAN.

Variabel kuesioner mengacu pada variabel WebQual (Barus et al., 2018; Sastika, 2016; Shia, Chen, Ramdansyah, \& Wang, 2016) yang terdiri dari (1) Kemudahan Penggunaan (Usability), meliputi mudah untuk ditelusuri, digunakan, dipelajari, dimengerti, menarik, interface menyenangkan, kompetensi yang baik, dan memberikan pengalaman baru yang menyenangkan; (2) Kualitas Informasi (Information quality) meliputi informasi yang dipercaya, akurat, terkini, mudah dimengerti, detail, dan informasi yang disajikan sesuai dengan format desain; dan (3) Kualitas Interaksi Layanan (Service interaction quality) meliputi rasa aman bertransaksi, reputasi yang baik, mudahnya komunikasi, mempunyai kepercayaan menyimpan informasi, memberi keyakinan untuk janji yang disampaikan akan ditepati.

Uji validitas dan reliabilitas kuesioner dilakukan kepada 30 responden dan diolah dengan program SPSS (Prayitno, 2018), dengan ketentuan: (1) jika nilai $r_{\text {hitung }} \geq r_{\text {tabel }}$ dengan tingkat signifikan 5\%, maka variabel instrumen dinyatakan valid, sedangkan jika nilai $\mathrm{r}_{\text {-hitung }}<\mathrm{r}_{\text {tabel }}$ maka variabel instrumen dalam kuesioner dinyatakan tidak valid (Sugiyono, 2016); dan (2) jika nilai Cronbach's Alpha $\geq 0,7$ maka variabel instrumen dikatakan reliabel, sedangkan jika nilai Cronbach's Alpha < 0,7 maka variabel instrumen dikatakan tidak reliabel (Ghozali, 2016).

Jumlah sampel sebanyak 193 dari populasi 1.265 pegawai LAPAN yang tersebar pada 21 Satuan Kerja di lingkungan LAPAN. Jumlah sampel ini telah memenuhi jumlah minimum sampel dengan tingkat kesalahan 10\% berdasarkan rumus Slovin (Napitupulu, 2016). Jumlah sampel tersebut terdiri dari: 13 responden dari Pusat Teknologi dan Data Penginderaan Jauh (Pustekdata); 26 responden dari Pusat Pemanfaatan Penginderaan Jauh (Pusfatja); 11 responden dari Pusat Sains dan Teknologi Atmosfer (PSTA); 14 responden dari Pusat Sains Antariksa (Pussainsa); 25 responden dari Pusat Teknologi Roket (Pustekroket); 17 responden dari Pusat Teknologi Penerbangan (Pustekbang); 15 responden dari Pusat Teknologi Satelit (Pusteksat): 3 responden dari Pusat Kajian Kebijakan Penerbangan dan Antariksa (PusKKPA); 4 responden dari Pusat Inovasi dan Standar Penerbangan dan Antariksa (Pussispan); 9 responden dari Pusat Teknologi Informasi dan Komunikasi Penerbangan dan Antariksa (Pustikpan); 6 responden dari Biro Perencanaan dan Keuangan (Biro Renkeu); 6 responden dari Biro Sumber Daya Manusia, Organisasi dan Hukum (Biro SDM Orkum); 14 responden dari Biro Kerja Sama, Hubungan Masyarakat dan Umum (Biro KSHU); 3 responden dari Inspektorat; 3 responden dari SBPJ 
(Stasiun Bumi Penginderaan Jauh) Parepare; 3 responden dari BPAA (Balai Pengamatan Antariksa dan Atmosfer), Sumedang; 4 responden dari BPAA, Pasuruan; 4 responden dari BPAA, Agam; 3 responden dari BPAA, Pontianak; 5 responden dari BPAA dan Uji Teknologi, Garut; dan 5 responden dari BPAA, Kendali Satelit dan Penginderaan Jauh, Biak.

Teknik penentuan sampel menggunakan Purposive Sampling dan Proporsional Sampling sehingga tidak dilakukan pada seluruh populasi tetapi terfokus pada target. Dengan mempertimbangkan kriteria-kriteria tertentu sesuai dengan tujuan penelitian, pengambilan sampel dari masing-masing satuan kerja di lingkungan LAPAN sesuai dengan jumlah populasi pegawai LAPAN yang ada pada masing-masing Satuan Kerja. Hal ini dimaksudkan untuk lebih memenuhi keterwakilan sampel yang diambil terhadap populasi. Pengambilannya melalui pengiriman kuesioner kepada pegawai LAPAN sebagai responden yang bukan responden pada uji instrumen kuesioner untuk memberikan tanggapan terhadap website LAPAN. Pengambilan data penelitian ini dilakukan pada tanggal 23 April 2020 hingga 20 Mei 2020.

Analisis data pada penelitian ini menggunakan Analisis Regresi Linier Berganda yang harus memenuhi beberapa uji asumsi klasik (Prayitno, 2018), antara lain residual berdistribusi normal, tidak adanya heteroskedastisitas, tidak adanya korelasi, tidak adanya multikolinieritas, dan linieritas. Analisis regresi pada penelitian ini digunakan untuk melihat ada tidaknya pengaruh yang signifikan antara variabel bebas (X1, X2, X3) dengan variabel terikat (Y). Selain itu, juga untuk melihat bagaimana pengaruhnya (positif atau negatif) dan seberapa besar pengaruhnya. Model persamaan regresi berganda (Sugiyono, 2016; Wardhana, 2015) sebagai berikut:

$$
\mathrm{Y}=\mathrm{a}+\mathrm{b} 1 \mathrm{X} 1+\mathrm{b} 2 \mathrm{X} 2+\mathrm{b} 3 \mathrm{X} 3+\mathrm{e}
$$

dengan keterangan: Y adalah nilai variabel terikat (tingkat kepuasan); a adalah konstanta; b1, b2, dan b3 adalah koefisien regresi; X1, X2, X3 adalah variabel bebas; dan e adalah error (diasumsikan bernilai nol).

Uji signifikansi pengaruh variabel Usability (X1), variabel Information Quality (X2), dan variabel Service Interaction Quality (X3) terhadap kepuasan pengguna website LAPAN (Y), dilakukan secara simultan maupun secara parsial dengan taraf signifikansi sebesar 5\% $(\alpha=0,05)$, sebagai berikut:

1. Uji F, merupakan metode pengujian dalam statistik yang digunakan untuk menguji apakah variabel X1, X2, X3 secara simultan berpengaruh terhadap Y. Dengan ketentuan jika nilai $\mathrm{F}_{\text {hitung }} \geq \mathrm{F}_{\text {tabel }}$ maka $\mathrm{H}_{0}$ ditolak dan $\mathrm{H}_{1}$ diterima. Ini berarti terdapat pengaruh yang signifikan antara variabel X1, X2, X3 secara simultan terhadap Y. Sebaliknya jika nilai $F_{\text {hitung }}<F_{\text {tabel }}$ maka $\mathrm{H}_{0}$ diterima dan $\mathrm{H}_{1}$ ditolak. Ini berarti tidak terdapat pengaruh yang signifikan antara variabel X1, X2, X3 secara simultan terhadap Y.

2. Uji t, merupakan metode pengujian dalam statistik yang digunakan untuk menguji apakah variabel X1, X2, X3 secara parsial berpengaruh terhadap Y. Dengan ketentuan jika nilai $t_{\text {hitung }}$ $\geq t_{\text {tabel}}$, maka $\mathrm{H}_{0}$ ditolak dan $\mathrm{H}_{1}$ diterima. Ini berarti terdapat pengaruh yang signifikan antara variabel X1, X2, X3 secara parsial terhadap Y. Sebaliknya jika nilai $\mathrm{t}_{\text {hitung }}<\mathrm{t}_{\text {tabel }}$ maka $\mathrm{H}_{0}$ diterima dan $\mathrm{H}_{1}$ ditolak. Ini berarti tidak terdapat pengaruh yang signifikan antara variabel $\mathrm{X} 1$, $\mathrm{X} 2, \mathrm{X} 3$ secara parsial berpengaruh terhadap Y.

Koefisien determinasi $\left(\mathrm{R}^{2}\right)$ untuk mengetahui seberapa besar kontribusi variabel X1, X2, X3 secara simultan berpengaruh terhadap Y. Nilai koefisien determinasi ini berada pada interval antara nol hingga satu $\left(0 \leq \mathrm{R}^{2} \leq 1\right)$. Semakin besar nilai $\mathrm{R}^{2}$ (mendekati satu), maka pengaruh variabel $\mathrm{X} 1$, $\mathrm{X} 2$, X3 secara simultan terhadap $\mathrm{Y}$ akan semakin besar. Sebaliknya, jika $\mathrm{R}^{2}$ semakin kecil 
(mendekati nol) maka pengaruh variabel $\mathrm{X} 1, \mathrm{X} 2, \mathrm{X} 3$ secara simultan terhadap $\mathrm{Y}$ juga semakin kecil (Prayitno, 2018).

\section{HASIL DAN PEMBAHASAN}

\subsection{Karakteristik Responden}

Berdasarkan data yang berhasil dikumpulkan, jumlah responden yang mengembalikan kuesioner ada 193 orang pegawai LAPAN. Jumlah responden ini sudah melebihi dari jumlah sampel minimal yang dipersyaratkan Slovin dengan margin of error sebesar 10\% (Napitupulu, 2016). Karakteristik responden berdasarkan jenis kelamin, didominasi oleh responden laki-laki (64\%), sedangkan sisanya berjenis kelamin perempuan. Pendidikan responden paling banyak S1 (70\%), sedangkan sisanya berpendidikan S3, S2, SLTA/Diploma. Responden paling banyak menduduki jabatan fungsional (77\%), sedangkan sisanya pejabat Struktural, Koordinator dan Subkoordinator. Usia responden mayoritas antara 20-30 tahun (41\%) dan paling sedikit berusia 5160 tahun (10\%) sedangkan sisanya berada pada rentang usia yang lain. Responden paling banyak berasal dari Satuan Kerja Pusfatja (13,57\%) sedangkan sisanya berasal dari Satuan Kerja yang lain (Tabel 1).

Tabel 1. Karakteristik responden

\begin{tabular}{|c|c|c|}
\hline Aspek & Kategori & Responden \\
\hline \multirow{2}{*}{ Jenis Kelamin } & Laki-laki & 124 \\
\hline & Perempuan & 69 \\
\hline \multirow{4}{*}{ Usia } & 20-30 tahun & 80 \\
\hline & $31-40$ tahun & 63 \\
\hline & $41-50$ tahun & 31 \\
\hline & 51-60 tahun & 19 \\
\hline \multirow{4}{*}{ Jabatan } & Struktural & 10 \\
\hline & Koordinator & 10 \\
\hline & Subkoordinator & 14 \\
\hline & Fungsional & 159 \\
\hline \multirow{4}{*}{ Pendidikan } & SLTA/Diploma & 10 \\
\hline & Strata $1(\mathrm{~S} 1)$ & 130 \\
\hline & Strata $2(\mathrm{~S} 2)$ & 47 \\
\hline & Strata 3 (S3) & 6 \\
\hline \multirow{21}{*}{ Satuan Kerja } & Pustekdata & 13 \\
\hline & Pusfatja & 26 \\
\hline & PSTA & 11 \\
\hline & Pussainsa & 14 \\
\hline & Pustekroket & 25 \\
\hline & Pustekbang & 17 \\
\hline & Pusteksat & 15 \\
\hline & PusKKPA & 3 \\
\hline & Pussispan & 4 \\
\hline & Pustikpan & 9 \\
\hline & Biro Renkeu & 6 \\
\hline & Biro SDM Orkum & 6 \\
\hline & Biro KSHU & 14 \\
\hline & Inspektorat & 3 \\
\hline & SBPJ Parepare & 3 \\
\hline & BPAA Sumedang & 3 \\
\hline & BPAA Pasuruan & 4 \\
\hline & BPAA Agam & 4 \\
\hline & BPAA Pontianak & 3 \\
\hline & BPAA dan Uji Teknologi, Garut & 5 \\
\hline & BPAA Kendali Satelit dan Penginderaan Jauh, Biak & 5 \\
\hline
\end{tabular}




\subsection{Uji Validitas dan Reliabilitas}

Instrumen penelitian ini, sebelum dikirimkan kepada responden sudah dilakukan uji validitas dan reliabilitas kepada 30 responden di luar responden penelitian. Pengujian diolah dengan menggunakan IBM SPSS versi 20 , hasil uji validitasnya diperoleh nilai $\mathrm{r}_{\text {hitung }}$ pada kolom "Corrected Item-Total Correlation untuk setiap variabel instrumen berkisar antara interval 0,566 hingga 0,898 (Tabel 2). Karena nilai $r_{\text {hitung }} \geq r_{\text {tabel }}=0,3610$ dengan uji dua sisi untuk sampel $(n)=30$ dan tingkat signifikansi $\alpha=0,05$ maka variabel instrumen dalam kuesioner dinyatakan valid (Sugiyono, 2016). Sementara, hasil uji reliabilitasnya diperoleh nilai Cronbach's Alpha sebesar 0,958 (Tabel 3). Karena nilai nilai Cronbach's Alpha > 0,70, semua variabel instrumen dalam kuesioner dinyatakan reliabel (Ghozali, 2016).

Hasil uji validitas dan reliabilitas penelitian ini, semakin memperkuat hasil penelitian yang dilakukan pada website CV. Zamrud Multimedia Network (Syaifullah \& Soemantri, 2016), website Universitas Narotama (Wawoluamaya, Sunarto, \& Wulandari, 2016) dan XYZ University (Napitupulu, 2017), website Universitas XYZ (Amelia \& Pradesan, 2019), yang menegaskan hasil uji semua instrumen yang digunakan pada penelitian telah dinyatakan valid dan reliabel sehingga instrumen tersebut layak untuk digunakan sebagai alat pengumpulan data dalam penelitian. Namun demikian, berbeda dengan hasil penelitian yang dilakukan pada website Kementerian Kominfo (Sanjaya, 2012) yang menyatakan ada beberapa pertanyaan pada instrumen yang dinyatakan tidak valid sehingga dikeluarkan dari model. Kemudian sisanya yang dinyatakan valid tersebut dilakukan uji validitas ulang dan sekaligus uji reliabilitas hingga semua instrumen dinyatakan valid dan reliabel.

Tabel 2. Hasil Uji Validitas Instrumen

\begin{tabular}{|c|c|c|}
\hline Variabel WebQual & $\begin{array}{l}\text { Corrected Item- } \\
\text { Total Correlation } \\
\left(\mathrm{r}_{\text {hitung }}\right)\end{array}$ & Kategori \\
\hline \multicolumn{3}{|l|}{ Dimensi Kemudahan Penggunaan (Usability) (X1) } \\
\hline 1. Website mudah dioperasikan & .641 & Valid \\
\hline 2. Website memiliki interaksi jelas dan mudah dimengerti & .618 & Valid \\
\hline 3. Website memiliki kemudahan bernavigasi & .745 & Valid \\
\hline 4. Website memiliki tampilan yang atraktif / menarik & 677 & Valid \\
\hline 5. Website memiliki desain sesuai dengan jenis website & .664 & Valid \\
\hline 6. Website mengandung nilai kompetensi & .749 & Valid \\
\hline 7. Website menciptakan pengalaman positif bagi pengguna & .640 & Valid \\
\hline 8. Kemudahan untuk menentukan alamat website & .586 & Valid \\
\hline \multicolumn{3}{|l|}{ Dimensi Kualitas Informasi (Information Quality) (X2) } \\
\hline 1. Website menyediakan informasi akurat & .746 & Valid \\
\hline 2. Website menyediakan informasi terpercaya & .750 & Valid \\
\hline Website menyediakan informasi relevan & .766 & Valid \\
\hline Website menyediakan informasi mudah dipahami & .730 & Valid \\
\hline Website memberikan informasi update & .744 & Valid \\
\hline Website menyediakan informasi detail pada level yang tepat & .898 & Valid \\
\hline Website menyajikan informasi dalam format yang tepat & .836 & Valid \\
\hline \multicolumn{3}{|l|}{ Dimensi Kualitas Interaksi (Interaction Quality) (X3) } \\
\hline Website mempunyai reputasi yang baik & .742 & Valid \\
\hline 2. Website menyediakan keamanan untuk melengkapi transaksi & 689 & Valid \\
\hline $\begin{array}{l}\text { 3. Website memberikan rasa aman dalam menyampaikan data } \\
\text { pribadi }\end{array}$ & .585 & Valid \\
\hline Website memberikan ruang untuk komunitas & .566 & Valid \\
\hline Website memberikan ruang untuk personalisasi & 620 & Valid \\
\hline Website menyediakan keamanan interaksi & .741 & Valid \\
\hline 7. Website menjaga informasi pribadi & .596 & Valid \\
\hline \multicolumn{3}{|l|}{ Overall Quality } \\
\hline 1. Pendapat secara umum tentang website LAPAN & .832 & Valid \\
\hline
\end{tabular}

Sumber: Data primer diolah, 2020 
Tabel 3. Hasil Uji Reliabilitas Instrumen

\begin{tabular}{cc}
\multicolumn{2}{c}{ Reliability Statistics } \\
\hline Cronbach's Alpha & N of Items \\
\hline .958 & 23 \\
\hline \multicolumn{2}{c}{ Sumber: Data primer diolah, 2020}
\end{tabular}

\subsection{Hasil Uji Asumsi Klasik Regresi Linier}

Hasil uji asumsi klasik ini diperlukan untuk memenuhi persyaratan yang diperlukan dalam penggunaan Analisis Regresi Linier Berganda terdiri dari Uji Normal Residual, Uji Heteroskedastisitas, Uji Multikolinieritas, dan Uji Linieritas (Prayitno, 2018). Pengujian asumsi klasik ini, dapat ditentukan sebagai berikut:

1. Uji Normal Residual

Uji ini untuk melihat apakah nilai residual yang dihasilkan dari regresi terdistribusi secara normal atau tidak. Model regresi yang baik adalah yang memiliki residual terdistribusi secara normal (Prayitno, 2018). Berdasarkan hasil uji normalitas dengan metode grafik pada Grafik Normal P-P Plot of Regression standardized residual (Gambar 3), terlihat bahwa titik-titik menyebar sekitar garis dan mengikuti garis diagonal maka nilai residual tersebut telah normal sehingga data yang digunakan pada penelitian ini memiliki distribusi yang normal untuk uji asumsi normalitas.

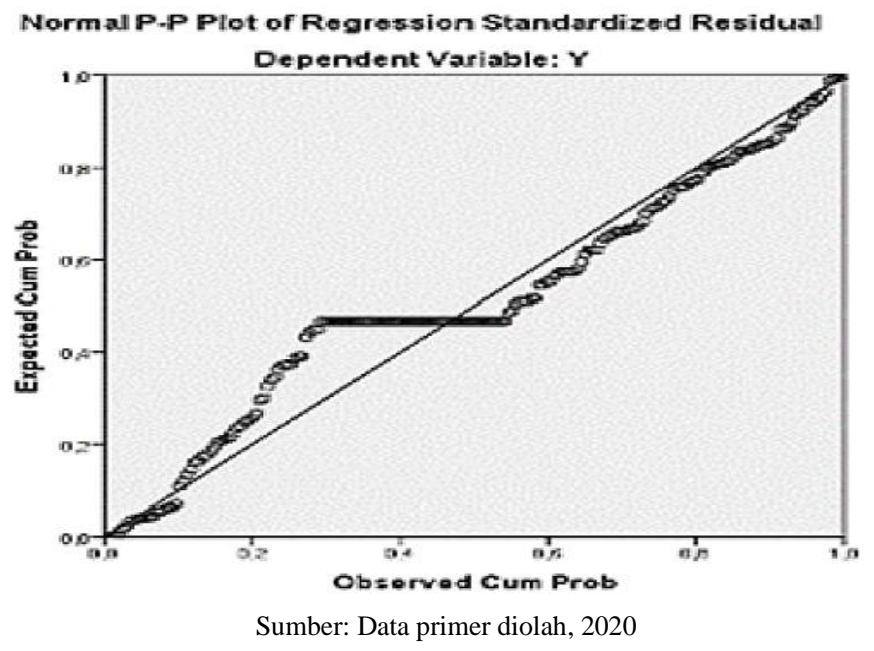

Gambar 3. Hasil Uji Normal P-P Plot of Regression Standardized Residual

2. Uji Heteroskedastisitas

Uji ini untuk melihat apakah model regresi terjadi kesamaan varians dari residual pengamatan ke pengamatan yang lain (Prayitno, 2018). Berdasarkan hasil uji heteroskedastisitas pada grafik pola titik-titik pada scatterplots antara standardized predicted value (ZPRED) dengan standardized residual (SRESID) (Gambar 4), terlihat bahwa titik-titik tidak membentuk pola yang jelas atau tertentu sehingga disimpulkan residual memiliki varians yang konstan atau tidak terjadi masalah heteroskedastisitas dalam model regresi. 


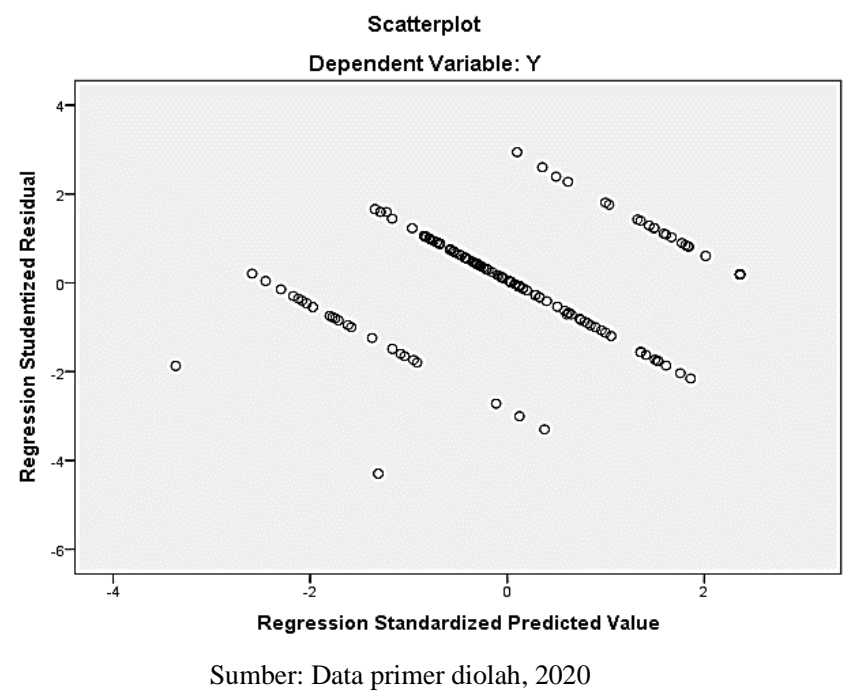

Gambar 4. Scatterplot

3. Uji Multikoliniertas

Uji ini untuk melihat ada tidaknya korelasi yang sempurna atau mendekati sempurna antar variabel independen (Prayitno, 2018). Berdasarkan hasil uji multikolinieritas untuk nilai toleransi dan VIF (Variance Inflation Factory) pada model regresi (Tabel 4), terlihat bahwa nilai toleransi untuk variabel X1 sebesar 0,393, X2 sebesar 0,97, dan X3 sebesar 0,945. Nilai VIF untuk X1 sebesar 2,544, X2 sebesar 2,519 dan X3 sebesar 2,019. Oleh karena nilai toleransi seluruh variabel lebih besar dari 0,10 dan nilai VIF seluruhnya kurang dari 10, maka disimpulkan tidak terjadi atau bebas dari masalah multikolinieritas pada model regresi.

Tabel 4. Hasil Uji Multikolinieritas

\begin{tabular}{|c|c|c|c|c|c|c|c|c|}
\hline \multicolumn{9}{|c|}{ Coefficients $^{\mathrm{a}}$} \\
\hline \multirow{2}{*}{\multicolumn{2}{|c|}{ Model }} & \multicolumn{2}{|c|}{$\begin{array}{l}\text { Unstandardized } \\
\text { Coefficients }\end{array}$} & \multirow{2}{*}{$\begin{array}{l}\text { Standardized } \\
\text { Coefficients } \\
\text { Beta }\end{array}$} & \multirow[t]{2}{*}{$\mathrm{t}$} & \multirow[t]{2}{*}{ Sig. } & \multicolumn{2}{|c|}{ Collinearity Statistics } \\
\hline & & $\mathrm{B}$ & Std. Error & & & & Tolerance & VIF \\
\hline \multirow{4}{*}{1} & (Constant) & .305 & .188 & & 1.621 & .107 & & \\
\hline & $\mathrm{X} 1$ & .067 & .010 & .504 & 6.739 & .000 & .393 & 2.544 \\
\hline & $\mathrm{X} 2$ & .016 & .014 & .087 & 1.172 & .243 & .397 & 2.519 \\
\hline & X3 & .037 & .010 & .248 & 3.712 & .000 & .495 & 2.019 \\
\hline
\end{tabular}

Sumber: Data primer diolah, 2020

4. Uji Linieritas

Uji ini untuk melihat apakah dua variabel mempunyai hubungan yang linier secara signifikan atau tidak (Prayitno, 2018). Data yang baik seharusnya terdapat hubungan yang linier antara variabel X1, X2, X3 terhadap Y. Berdasarkan hasil uji linieritas menunjukkan bahwa:

a. Nilai signifikansi pada linearity antara $\mathrm{X} 1$ dengan $\mathrm{Y}$ adalah sebesar $0,000<0,05$ artinya terdapat hubungan yang linier antara variabel $\mathrm{X} 1$ dengan variabel $\mathrm{Y}$ (Tabel 5).

Tabel 5. Hasil Uji Liniertas antara Variabel X1 dengan Y

\begin{tabular}{|c|c|c|c|c|c|c|c|}
\hline \multicolumn{8}{|c|}{ ANOVA Table } \\
\hline & & & $\begin{array}{l}\text { Sum of } \\
\text { Squares }\end{array}$ & $\mathrm{df}$ & $\begin{array}{l}\text { Mean } \\
\text { Square }\end{array}$ & $\mathrm{F}$ & Sig. \\
\hline \multirow{5}{*}{$\mathrm{Y} * \mathrm{X} 1$} & \multirow{3}{*}{$\begin{array}{l}\text { Between } \\
\text { Groups }\end{array}$} & (Combined) & 35.862 & 19 & 1.887 & 18.085 & .000 \\
\hline & & Linearity & 29.060 & 1 & 29.060 & 278.442 & .000 \\
\hline & & $\begin{array}{l}\text { Deviation from } \\
\text { Linearity }\end{array}$ & 6.802 & 18 & .378 & 3.621 & .000 \\
\hline & \multicolumn{2}{|c|}{ Within Groups } & 18.055 & 173 & .104 & & \\
\hline & \multicolumn{2}{|l|}{ Total } & 53.917 & 192 & & & \\
\hline
\end{tabular}


b. Nilai signifikansi pada linearity antara X2 dengan $\mathrm{Y}$ adalah sebesar 0,007 $<0,05$ artinya terdapat hubungan yang linier antara variabel X2 dengan variabel $\mathrm{Y}$ (Tabel 6).

Tabel 6. Hasil Uji Liniertas antara Variabel X2 dengan Y

\begin{tabular}{|c|c|c|c|c|c|c|c|}
\hline \multicolumn{8}{|c|}{ ANOVA Table } \\
\hline & & & $\begin{array}{l}\text { Sum of } \\
\text { Squares }\end{array}$ & df & $\begin{array}{l}\text { Mean } \\
\text { Square }\end{array}$ & $\mathrm{F}$ & Sig. \\
\hline \multirow{5}{*}{$\mathrm{Y} * \mathrm{X} 2$} & \multirow{3}{*}{$\begin{array}{l}\text { Between } \\
\text { Groups }\end{array}$} & (Combined) & 25.943 & 14 & 1.853 & 11.791 & .000 \\
\hline & & Linearity & 21.147 & 1 & 21.147 & 134.561 & .000 \\
\hline & & $\begin{array}{l}\text { Deviation from } \\
\text { Linearity }\end{array}$ & 4.796 & 13 & .369 & 2.347 & .007 \\
\hline & \multicolumn{2}{|c|}{ Within Groups } & 27.974 & 178 & .157 & & \\
\hline & \multicolumn{2}{|l|}{ Total } & 53.917 & 192 & & & \\
\hline
\end{tabular}

Sumber: Data primer diolah, 2020

c. Nilai signifikansi pada linearity antara X3 dengan $\mathrm{Y}$ adalah sebesar $0,005<0,05$ artinya terdapat hubungan yang linier antara variabel X3 dengan variabel $\mathrm{Y}$ (Tabel 7).

Tabel 7. Hasil Uji Liniertas antara Variabel X3 dengan Y

\begin{tabular}{|c|c|c|c|c|c|c|c|}
\hline \multicolumn{8}{|c|}{ ANOVA Table } \\
\hline & & & $\begin{array}{l}\text { Sum of } \\
\text { Squares }\end{array}$ & df & $\begin{array}{l}\text { Mean } \\
\text { Square }\end{array}$ & $\mathrm{F}$ & Sig. \\
\hline \multirow{5}{*}{$\mathrm{Y} * \mathrm{X} 3$} & \multirow{3}{*}{$\begin{array}{l}\text { Between } \\
\text { Groups }\end{array}$} & (Combined) & 27.808 & 18 & 1.545 & 10.296 & .000 \\
\hline & & Linearity & 22.152 & 1 & 22.152 & 147.631 & .000 \\
\hline & & $\begin{array}{l}\text { Deviation from } \\
\text { Linearity }\end{array}$ & 5.655 & 17 & .333 & 2.217 & .005 \\
\hline & \multicolumn{2}{|c|}{ Within Groups } & 26.109 & 174 & .150 & & \\
\hline & \multicolumn{2}{|l|}{ Total } & 53.917 & 192 & & & \\
\hline
\end{tabular}

Dari analisis uji asumsi klasik tersebut, dapat diinterpretasikan bahwa hasil uji asumsi klasik yang meliputi Uji Normal Residual, Uji Heteroskedastisitas, Uji Multikoliniertas, dan Uji Linieritas secara keseluruhan dapat dikatakan telah memenuhi persyaratan yang diperlukan dalam penggunaan Analisis Regresi Linier Berganda. Hasil uji asumsi klasik penelitian ini, semakin memperkuat hasil penelitian yang dilakukan pada website PPDB terhadap kepuasan pengguna (Utami, Ishaq, \& Maulidiyah, 2018) dan Website BPS Ka. Siak (Nofirman, Jalinus, \& Irfan, 2019) yang menegaskan seluruh uji asumsi klasik yang dilakukan pada penelitian tersebut telah dinyatakan memenuhi persyaratan yang diperlukan untuk penggunaan Analisis Regresi Linier Berganda.

\subsection{Uji Regresi Linier Berganda}

Hasil uji regresi linier berganda antara variabel X1, X2, X3 terhadap Y disajikan pada Tabel 8.

Tabel 8. Hasil Uji Regresi Linier Berganda

\begin{tabular}{|c|c|c|c|c|c|c|}
\hline \multicolumn{7}{|c|}{ Coefficients $^{\mathrm{a}}$} \\
\hline \multirow{2}{*}{ Model } & & \multicolumn{2}{|c|}{$\begin{array}{l}\text { Unstandardized } \\
\text { Coefficients }\end{array}$} & \multirow{2}{*}{$\begin{array}{l}\text { Standardized } \\
\text { Coefficients } \\
\text { Beta } \\
\end{array}$} & \multirow{2}{*}{$\mathrm{t}$} & \multirow[t]{2}{*}{ Sig. } \\
\hline & & $\mathrm{B}$ & Std. Error & & & \\
\hline \multirow{4}{*}{1} & (Constant) & .305 & .188 & & 1.621 & .107 \\
\hline & $\mathrm{X} 1$ & .067 & .010 & .504 & 6.739 & .000 \\
\hline & $\mathrm{X} 2$ & .016 & .014 & .087 & 1.172 & .243 \\
\hline & $\mathrm{X} 3$ & .037 & .010 & .248 & 3.712 & .000 \\
\hline
\end{tabular}

a. Dependent Variable: YX

Sumber: Data primer diolah, 2020

Dengan memasukkan nilai konstanta dan koefisien regresi dari Tabel 8 ke persamaan (1) maka model persamaan regresi linier berganda (Sugiyono, 2016; Wardhana, 2015), dapat ditulis: 
$\mathrm{Y}=0,305+0,067 \mathrm{X} 1+0,016 \mathrm{X} 2+0,037 \mathrm{X} 3$

dengan ketentuan: $\mathrm{Y}$ adalah tingkat kepuasan pengguna website LAPAN; $\mathrm{X} 1$ adalah variabel kemudahan penggunaan (Usability); X2 adalah variabel kualitas informasi (Information Quality); dan X3 adalah variabel kualitas interaksi layanan (Service Interaction Quality).

Dari persamaan (2), dapat dijelaskan pengaruh perubahan variabel X1, X2, X3 terhadap Y (Napitupulu, 2017; Sugiyono, 2016; Wardhana, 2015) sebagai berikut:

a. Nilai konstanta adalah 0,305 merupakan nilai Y jika ketiga variabel X1, X2, X3 bernilai nol, artinya adanya kenaikkan $\mathrm{Y}$ sangat ditentukan dari nilai konstanta tersebut.

b. Nilai koefisien variabel X1 adalah 0,067. Artinya pengaruh variabel X1 terhadap Y akan meningkatkan kepuasan pengguna website LAPAN sebesar 6,7\% dengan asumsi variabel bebas X2 dan X3 adalah konstan. Tanda (+) dari koefisien variabel X1 pada persamaan (2), dapat diinterpretasikan bahwa variabel Usability (X1) dengan kepuasan pengguna website LAPAN (Y) memiliki hubungan yang searah atau positif.

c. Nilai koefisien variabel X2 adalah 0,016. Artinya pengaruh variabel X2 terhadap Y akan meningkatkan sebesar 0,016 dengan asumsi variabel bebas X1 dan X3 adalah konstan. Tanda (+) dari koefisien variabel X2 pada persamaan (2), dapat diinterpretasikan bahwa variabel Information Quality (X2) dengan kepuasan pengguna website LAPAN (Y) memiliki hubungan yang searah atau positif.

d. Nilai koefisien variabel X3 adalah 0,037. Artinya pengaruh variabel X3 terhadap Y akan meningkatkan kepuasan pengguna website LAPAN sebesar 3,7\% dengan asumsi variabel bebas X1 dan X2 adalah konstan. Tanda (+) dari koefisien variabel X3 pada persamaan (2), dapat diinterpretasikan bahwa variabel Interaction Quality (X3) dengan kepuasan pengguna website LAPAN (Y) memiliki hubungan yang searah atau positif.

Dari analisis tersebut, diperoleh pengaruh variabel bebas terhadap Y adalah 0,067 untuk X1, 0,016 untuk X2, dan 0,037 untuk X3. Hal ini dapat diinterpretasikan bahwa variabel bebas yang memberikan pengaruh paling dominan terhadap kepuasan pengguna website LAPAN adalah variabel Usability (6,7\%) dibanding dengan pengaruh variabel Information Quality (1,6\%), dan pengaruh variabel Service Interaction Quality $(3,7 \%)$.

\subsection{Uji Korelasi dan Determinasi}

Hasil uji korelasi dan determinasi antara variabel X1, X2, X3 dengan Y disajikan pada Tabel 9.

Tabel 9. Koefisien Determinasi

\begin{tabular}{lllll}
\multicolumn{4}{c}{ Model Summary } \\
\hline Model & $\mathrm{R}$ & R Square & Adjusted R Square & Std. Error of the Estimate \\
\hline 1 & $.764^{\mathrm{a}}$ & .584 & .577 & .34461 \\
\hline \multicolumn{5}{l}{ a. Predictors: (Constant), X3, X2, X1 } \\
Sumber: Data primer diolah, 2020
\end{tabular}

Dari Tabel 9 dapat diketahui nilai R didapat 0,764 artinya korelasi antara variabel X1, X2, X3 terhadap Y adalah sebesar 0,764. Nilai tersebut dapat diinterpretasikan adanya hubungan yang erat antara Usability, Information Quality, dan Interaction Quality dengan kepuasan pengguna website LAPAN. Selain itu, juga dapat diketahui nilai R Square yang merupakan koefisien determinasi sebesar 0,584 artinya variabel Usability, Information Quality, dan Interaction Quality memberikan kontribusi pengaruh atau menjelaskan kepuasan pengguna website LAPAN sebesar 58,4\%, sedangkan sisanya sebesar 41,6\% dipengaruhi oleh variabel bebas lain yang tidak diteliti dalam penelitian ini. Keeratan hubungan yang ditunjukkan oleh nilai korelasi dan kontribusi variabel bebas terhadap variabel terikat yang ditunjukkan oleh nilai koefisien determinasi pada penelitian ini ternyata masih relatif jauh lebih rendah jika dibandingkan dengan hasil penelitian yang dilakukan 
pada Website BPS Ka. Siak yang memiliki nilai korelasi $(0,799)$ dengan koefisien determinasi $(63,8 \%)$ ((Nofirman, Jalinus, \& Irfan, 2019)), dan pada website PPDB yang memiliki nilai korelasi $(0,803)$ dengan koefisien determinasi $(64,4 \%)$ (Utami, Ishak, \& Maulidiyah, 2018).

\subsection{Uji Hipotesis}

Uji hipotesis untuk melihat pengaruh variabel X1, X2, X3 secara simultan terhadap Y dilakukan melalui uji F dan secara parsial dilakukan melalui uji t (Prayitno, 2018), sebagai berikut:

a) Uji F

Uji hipotesis pengaruh variabel $\mathrm{X} 1, \mathrm{X} 2, \mathrm{X} 3$ secara simultan terhadap Y pada penelitian ini dilakukan dengan memberikan hipotesis alternatif $\left(\mathrm{H}_{1}\right)$ adalah terdapat pengaruh positif dan signifikan antara variabel $\mathrm{X} 1, \mathrm{X} 2, \mathrm{X} 3$ secara simultan terhadap $\mathrm{Y}$; dan hipotesis nol $\left(\mathrm{H}_{\mathrm{o}}\right)$ adalah tidak terdapat pengaruh positif dan signifikan antara variabel X1, X2, X3 secara simultan terhadap Y. Hasil uji F tersebut dapat dilihat pada Tabel 10.

Tabel 10. Analisis Variansi

\begin{tabular}{lllllll}
\multicolumn{7}{c}{ ANOVA $^{\mathrm{a}}$} \\
\hline Model & Sum of Squares & df & Mean Square & F & Sig. \\
\hline \multirow{2}{*}{1} & Regression & 31.472 & 3 & 10.491 & 88.336 & $.000^{\mathrm{b}}$ \\
& Residual & 22.445 & 189 & .119 & & \\
\hline & Total & 53.917 & 192 & & & \\
\hline
\end{tabular}

a. Dependent Variable: YX

b. Predictors: (Constant), X3, X2, X1

Sumber: Data primer diolah, 2020

Berdasarkan Tabel 10, hasil uji menunjukkan bahwa nilai $\mathrm{F}_{\text {hitung }}(88,336)>\mathrm{F}_{\text {tabel }}(2,69)$ dan nilai signifikansi $0,000<0,05$ maka Ho ditolak dan $\mathrm{H} 1$ diterima. Ini berarti variabel X1, X2, X3 berpengaruh positif dan signifikan secara simultan terhadap Y. Kondisi ini dapat memberikan dampak bahwa jika kualitas variabel Usability, Information Quality, dan Interaction Quality adalah baik, maka kepuasan pengguna website LAPAN akan meningkat. Namun sebaliknya, jika kualitas variabel Usability, Information Quality, dan Interaction Quality adalah tidak baik, maka kepuasan pengguna website LAPAN akan menurun. Hasil penelitian ini semakin memperkuat hasil penelitian yang dilakukan pada Website CV. Zamrud Multimedia Network (Sanjaya, 2012), Website Universitas Narotama (Wawoluamaya, Sunarto, \& Wulandari, 2016), Website Stikom Career Center (SCC) Surabaya (Jamalludin, Sulistiowati, \& Lemantara, 2016), pada website PPDB (Utami, Ishaq, \& Maulidiyah, 2018), Website BPS Ka. Siak (Nofirman, Jalinus, \& Irfan, 2019). yang menyimpulkan bahwa variabel Usability, Information Quality, dan Interaction Quality berpengaruh positif dan signifikan secara simultan terhadap kepuasan pengguna website tersebut.

b) Uji t

Hasil uji hipotesis pengaruh variabel $\mathrm{X} 1, \mathrm{X} 2, \mathrm{X} 3$ secara parsial terhadap $\mathrm{Y}$ dengan menggunakan uji t disajikan pada Tabel 11.

Tabel 11. Hasil Uji t

Coefficients $^{\mathrm{a}}$

\begin{tabular}{|c|c|c|c|c|c|c|}
\hline \multirow[t]{2}{*}{ Model } & & \multicolumn{2}{|c|}{$\begin{array}{l}\text { Unstandardized } \\
\text { Coefficients }\end{array}$} & \multirow{2}{*}{$\begin{array}{c}\begin{array}{l}\text { Standardized } \\
\text { Coefficients }\end{array} \\
\text { Beta } \\
\end{array}$} & \multirow[t]{2}{*}{$\mathrm{t}$} & \multirow[t]{2}{*}{ Sig. } \\
\hline & & $\mathrm{B}$ & Std. Error & & & \\
\hline \multirow{4}{*}{1} & (Constant) & .305 & .188 & & 1.621 & .107 \\
\hline & $\mathrm{X} 1$ & .067 & .010 & .504 & 6.739 & .000 \\
\hline & $\mathrm{X} 2$ & .016 & .014 & .087 & 1.172 & .243 \\
\hline & $\mathrm{X} 3$ & .037 & .010 & .248 & 3.712 & .000 \\
\hline
\end{tabular}

Berdasarkan Tabel 11, dapat dijelaskan pengaruh setiap variabel bebas X1, X2, X3 terhadap 
variabel terikat Y (Prayitno, 2018) sebagai berikut:

a. Pengaruh variabel Usability (X1) terhadap kepuasan pengguna (Y). Uji hipotesis untuk melihat pengaruh variabel X1 secara parsial terhadap Y dilakukan melalui Uji t dengan memberikan hipotesis alternatif $(\mathrm{H} 2)$ adalah terdapat pengaruh positif dan signifikan antara variabel $\mathrm{X} 1$ secara parsial terhadap $\mathrm{Y}$, dan hipotesis nol $\left(\mathrm{H}_{0}\right)$ adalah tidak terdapat pengaruh positif dan signifikan antara variabel X1 secara parsial terhadap Y. Berdasarkan Tabel 11, hasil uji menunjukkan bahwa variabel X1 memiliki nilai $t_{\text {hitung }}(6,739)>t_{\text {tabel }}$ $(1,972)$ dan nilai signifikan sebesar $0,000<0,05$ maka $\mathrm{H}_{0}$ ditolak dan $\mathrm{H} 2$ diterima. Hasil ini menjelaskan bahwa terdapat pengaruh yang signifikan antara variabel X1 secara parsial terhadap Y. Ini berarti semakin baik kualitas layanan variabel Usability (X1) maka kepuasan pengguna website LAPAN (Y) akan semakin meningkat, sebaliknya jika kualitas layanan variabel Usability (X1) tidak baik maka kepuasan pengguna website LAPAN (Y) akan semakin menurun.

b. Pengaruh variabel Quality Information (X2) terhadap kepuasan pengguna (Y).Uji hipotesis untuk melihat pengaruh variabel X2 secara parsial terhadap Y dilakukan melalui Uji t dengan memberikan hipotesis alternatif (H3) adalah terdapat pengaruh positif dan signifikan antara variabel $\mathrm{X} 2$ secara parsial terhadap $\mathrm{Y}$, dan hipotesis nol $\left(\mathrm{H}_{0}\right)$ adalah tidak terdapat pengaruh yang signifikan antara variabel X2 secara parsial terhadap Y. Berdasarkan Tabel 11, hasil uji menunjukkan bahwa variabel X2 memiliki nilai $t_{\text {hitung }}$ $(1,172)<t_{\text {tabel }}(1,972)$ dan nilai signifikan sebesar 0,243>0,05 maka $\mathrm{H}_{0}$ diterima dan $\mathrm{H} 3$ ditolak. Hasil ini menjelaskan bahwa tidak terdapat pengaruh positif dan signifikan antara variabel X2 secara parsial terhadap Y.

c. Pengaruh variabel Service Interaction Quality (X3) terhadap kepuasan (Y). Uji hipotesis untuk melihat pengaruh variabel X3 secara parsial terhadap Y melalui Uji t dengan memberikan hipotesis alternatif $(\mathrm{H} 4)$ adalah terdapat pengaruh positif dan signifikan antara variabel X3 secara parsial terhadap $\mathrm{Y}$, dan hipotesis nol $\left(\mathrm{H}_{0}\right)$ adalah tidak terdapat pengaruh positif dan signifikan antara variabel X3 secara parsial terhadap Y. Berdasarkan Tabel 11, hasil uji menunjukkan bahwa variabel X3 memiliki nilai $t_{\text {hitung }}(3,712)>t_{\text {tabel }}$ $(1,972)$ dan nilai signifikan sebesar $0,000<0,05$, maka $\mathrm{H}_{0}$ ditolak dan $\mathrm{H} 4$ diterima. Hal ini menjelaskan bahwa terdapat pengaruh positif dan signifikan antara variabel X3 secara parsial terhadap Y. Ini berarti semakin baik layanan variabel Service Interaction Quality (X3) maka kepuasan pengguna website LAPAN (Y) akan semakin meningkat, sebaliknya jika layanan variabel Service Interaction Quality (X3) tidak baik maka kepuasan pengguna website LAPAN (Y) akan semakin menurun.

Dari analisis tersebut, dapat diinterpretasikan bahwa variabel $\mathrm{X} 1$ dan $\mathrm{X} 3$ berpengaruh positif dan signifikan secara parsial terhadap $\mathrm{Y}$, sedangkan variabel $\mathrm{X} 2$ tidak berpengaruh positif dan signifikan secara parsial terhadap Y. Hasil penelitian ini semakin memperkuat hasil penelitian yang dilakukan pada website Kementerian Kominfo (Sanjaya, 2012), website Backpaker Jakarta (Ispandi, Ramadan, Atmaja, \& Sudrajat, 2020), website PT. Badak LNG (Zamani, Sunarto, \& Mastan, 2016), dan website pada universitas XYZ (Napitupulu, 2017) yang menegaskan variabel yang berpengaruh positif dan signifikan secara parsial terhadap kepuasan pengguna (Y) adalah variabel Usability (X1) dan variabel Service Interaction Quality (X3), sedangkan variabel Information Quality (X2) tidak berpengaruh positif dan signifikan secara parsial terhadap kepuasan pengguna (Y). Namun, berbeda dengan hasil penelitian yang dilakukan pada website Galeri Medika (Sulistyowati \& Meisiana, 2019), dan website Pada Universitas XYZ (Amelia \& Pradesan, 2019), yang menyatakan variabel yang berpengaruh positif dan signifikan secara parsial adalah variabel 
Usability (X1), Information Quality (X2), sedangkan variabel Service Interaction Quality (X3) tidak berpengaruh positif dan signifikan secara parsial terhadap kepuasan pengguna tersebut.

\section{PENUTUP}

Model persamaan regresi berganda untuk kualitas website LAPAN adalah $\mathrm{Y}=0,305+0,067$ Usability + 0,016 Information Quality + 0,037 Service Interaction Quality. Variabel bebas yang berpengaruh paling dominan terhadap variabel Kepuasan Pengguna website LAPAN (Y) adalah variabel Usability (X1) sebesar 6,7\%, dibanding dengan variabel Information Quality (X2) yang hanya memberikan pengaruh sebesar 1,6\%, dan variabel Service Interaction Quality (X3) hanya sebesar $3,7 \%$.

Secara simultan variabel Usability (X1), Information Quality (X2), Service Interaction Quality (X3) berpengaruh positif dan signifikan terhadap variabel Kepuasan Pengguna website LAPAN (Y). Ketiga variabel Usability (X1), Information Quality (X2), Service Interaction Quality (X3) secara simultan memberikan kontribusi atau menjelaskan kepuasan sebesar 58,4\% terhadap variabel Kepuasan Pengguna website LAPAN (Y), sedangkan sisanya sebesar 41,6\% dipengaruhi oleh variabel bebas lain yang tidak diteliti dalam penelitian ini.

Secara parsial hanya variabel Usability (X1) dan variabel Service Interaction Quality (X3) berpengaruh positif dan signifikan terhadap kepuasan pengguna website LAPAN (Y), sedangkan variabel Information Quality (X2) tidak berpengaruh positif dan tidak signifikan terhadap kepuasan pengguna website website LAPAN (Y).

Hasil penelitian ini disarankan untuk dimanfaatkan oleh LAPAN melalui Pusat Teknologi Informasi dan Komunikasi Penerbangan dan Antariksa sebagai pengelola website LAPAN agar dapat memberikan perhatian lebih banyak terhadap Usability (X1) dan Service Interaction Quality (X3) karena berpengaruh positif dan signifikan terhadap kepuasan pengguna (Y). Pada Information Quality (X2) meskipun tidak berpengaruh positif dan signifikan terhadap kepuasan pengguna website LAPAN (Y), hal ini bisa menjadi catatan bagi LAPAN agar terus meningkatkan kualitas informasi yang merupakan konten dari website LAPAN karena data dan informasi penerbangan dan antariksa yang disampaikan kepada masyarakat akan sangat bermanfaat dapat diperoleh dengan cepat dan tepat secara online dari manapun dan kapanpun.

\section{Ucapan Terima Kasih}

Penulis mengucapkan terima kasih kepada seluruh pihak yang terlibat, terutama kepada Kepala Pusat Teknologi Informasi dan Komunikasi Penerbangan dan Antariksa LAPAN yang telah memfasilitasi penelitian ini.

\section{DAFTAR PUSTAKA}

Amelia, L., \& Pradesan, I. (2019). Pengukuran Kualitas Layanan Website Terhadap Kepuasan Pengguna pada Universitas XYZ dengan Menggunakan Metode Webqual 4.0. Jurnal Sistem dan Informatika (JSI), 14(1), 57-63. https://doi.org/10.30864/jsi.v14i1.249

Barus, E. E., Suprapto., \& Herlambang, A. D. (2018). Analisis Kualitas Website Tribunnews.com Menggunakan Metode Webqual dan Importance Performance Analysis. Jurnal Pengembangan Teknologi Informasi dan Ilmu Komputer, 2(4), 1483-1491. https://doi.org/10.1017/CBO9781107415324.004

Chmielarz, W., \& Zborowski, M. (2018). Analysis of e-Banking Websites' Quality with the Application of the TOPsIs Method - A Practical study. Procedia Computer Science, 126, 1964-1976. https://doi.org/10.1016/j.procS.2018.07.256 
Dewi, W. W. A., \& Naya, A. W. D. (2020). Pengaruh Webqual 4.0 Terhadap Minat Beli (Studi Kuantitatif pada E-Commerce Mataharimall.com). Jurnal Teknologi Informasi dan Komputer, 6(2), 226-237.

Fatmala, W. S., Suprapto., \& Rachmadi, A. (2018). Analisis Kualitas Layanan Website E-Commerce Berrybenka Terhadap Kepuasan Pengunjung Menggunakan Metode WebQual 4.0 dan Importance Performance Analysis (IPA). Jurnal Pengembangan Teknologi Informasi dan Ilmu Komputer, 2(1), 175-183.

Ghozali, N. (2016). Aplikasi Multivariate dengan Program IBM SPSS 23. Semarang: BPFE Universitas Diponegoro.

Ispandi., Ramadan, R., Atmaja, R. K., \& Sudradjat, A. (2020). Analisis Pengaruh Kualitas Website Backpaker Jakarta Terhadap Kepuasan Pengguna Dengan Metode Webqual. REMIK (Riset dan EJurnal Manajemen Informatika Komputer), 4(2), 32. https://doi.org/10.33395/remik.v4i2.10527

Jamalludin, A., Sulistiowati., \& Lemantara, J. (2016). Analisis Pengaruh Kualitas Website Terhadap Kepuasan Pengguna Berdasarkan Metode Webqual 4.0 pada Website Stikom Career Center (SCC) Surabaya. Jurnal Sistem informasi dan Komputer Akuntansi, 5(1), 159-172.

Kurniawati, R. A., Kusyanti, A., \& Mursityo, Y. T. (2018). Analisis Pengaruh Kualitas Website Terhadap Kepuasan Pelanggan Mister Aladin Dengan Menggunakan Webqual 4.0. Jurnal Pengembangan Teknologi Informasi dan Ilmu Komputer, 2(3), 1151-1160.

LAPAN. (2020). Website Lembaga Penerbangan dan Antariksa Nasional (LAPAN). Diambil dari www.lapan.go.id

Maslan, A. (2014). Pengukuran Kualitas Layanan Website Pemerintah Kota Batam Menggunakan Metode Webqual 4.0. Jurnal Ilmiah Informatika, 1(3).

Napitupulu, D. (2017). Analysis of Factors Affecting the Website Quality Based on Webqual Approach (Study Case: XYZ University). International Journal on Advanced Science, Engineering and Information Technology, 7(3), 792-798. https://doi.org/10.18517/ijaseit.7.3.1748

Napitupulu, D. B. (2016). Evaluasi Kualitas Website Universitas XYZ dengan Pendekatan Webqual. Buletin Pos dan Telekomunikasi, 14(1), 51-64. https://doi.org/10.17933/bpostel.2016.140105

Nofirman, N., Jalinus, N., \& Irfan, D. (2019). Pengaruh Kualitas Website BPS Kab. Siak Terhadap Kepuasan Pengguna Website Menggunakan Metode Webqual 4.0. INVOTEK: Jurnal Inovasi Vokasional dan Teknologi, 19(1), 129-138. https://doi.org/10.24036/invotek.v19i1.369

Prayitno, D. (2018). SPSS Panduan Mudah Olah Data Bagi Mahasiswa \& Umum. Yogyakarta: Andi.

Sanjaya, I. (2012). Pengukuran Kualitas Layanan Website Kementerian Kominfo dengan Menggunakan Metode Webqual 4.0. Jurnal Penelitian IPTEK-KOM, 14(1), 1-14. Diambil dari www.kominfo.go.id

Santoso, B. S., Anwar, M. F., \& Hermawati, S. (2015). Analisis Kualitas Website Menggunakan Metode Webqual dan Importance - Performance Analysis (IPA) pada Situs Kaskus. (September).

Sastika, W. (2016). Analisis Pengaruh Kualitas Website (Webqual 4.0) Terhadap Keputusan Pembelian Pada Website E-Commerce Traveloka (Studi Kasus: Pengguna Traveloka di Kota Bandung Tahun 2015). Seminar Nasional Teknologi Informasi dan Komunikasi. Diambil dari www.pegipegi.com,

Shia, B. C., Chen, M., Ramdansyah, A. D., \& Wang, S. (2016). Measuring Customer Satisfaction toward Localization Website by WebQual and Importance Performance Analysis (Case Study on AliexPress Site in Indonesia). American Journal of Industrial and Business Management, 06(02), 117-128. https://doi.org/10.4236/ajibm.2016.62012

Sugiyono. (2016). Metode Penelitian Kuantitatif, Kualitatif, dan $R \&$ D. Bandung: Alfabeta.

Sulistyowati, R., \& Meisiana, D. (2019). Evaluasi Kualitas dan Pengaruh Website Galeri Medika Terhadap Kepuasan Pelanggan Menggunakan Metode Webqual 4.0. Jurnal Algoritma, Logika dan Komputasi, 2(2), 170-175. https://doi.org/10.30813/j-alu.v2i2.1846

Syaifullah, \& Soemantri, D. O. (2016). Pengukuran Kualitas Website Menggunakan Metode Webqual 4.0 (Studi Kasus: CV. Zamrud Multimedia Network). Jurnal Rekayasa dan Manajemen Sistem Informasi, 2(1), 19-25.

Utami, L. A., Ishaq, A., \& Maulidiyah, N. (2018). Analisa Pengaruh Kualitas Website PPDB Terhadap Kepuasan Pengguna. Jurnal Penelitian Teknik Informatika, 3(1), 31-37.

Wardhana, A. (2015). Determinan Kualitas Layanan Internet Banking dengan Menggunakan Metode Webqual Versi 4.0 dan Pengaruhnya Terhadap Kepuasan Nasabah Top Brand E-Channel Bank di Indonesia. Jurnal Riset Manajemen, 4(1). https://doi.org/10.1017/CBO9781107415324.004

Wawoluamaya, E. A., Sunarto, D., \& Wulandari, S. H. E. (2016). Analisis Pengaruh Kualitas Website 
Terhadap Kepuasan Pengguna Berdasarkan Metode Webqual 4.0 pada Universitas Narotama. Jurnal Sistem informasi dan Komputer Akuntansi, 5(11), 159-172.

Zamani, U. I., Sunarto, D., \& Mastan, I. A. (2016). Analisis Pengaruh Kualitas Website PT Badak LNG Terhadap Kepuasan Pengguna Menggunakan Metode Webqual. JSIKA, 5(11), 1-8. Diambil dari https://jurnal.dinamika.ac.id/index.php/jsika/article/view/1387 